\author{
Krassen Nedeltchev \\ Marcel Arnold \\ Ralf Baumgartner \\ Gerald Devuyst \\ Paul Erne \\ Daniel Hayoz \\ Roman Sztajzel \\ Barbara Tettenborn \\ Heinrich P. Mattle
}

\section{Vascular risk factors in the Swiss population}

Received: 19 August 2004

Received in revised form:

28 December 2004

Accepted: 4 January 2005

Published online: 15 April 2005

K. Nedeltchev $\cdot$ M. Arnold ·

H. P. Mattle, MD (凶)

Dept. of Neurology

University Hospital of Bern

Freiburgstrasse 4

3010 Bern, Switzerland

Tel.: + 41-31/632-3332

Fax: + 41-31/632-9679

E-Mail: heinrich.mattle@insel.ch

R. Baumgartner

Dept. of Neurology

University of Zurich

Zurich, Switzerland

G. Devuyst

Dept. of Neurology

CHUV

Lausanne, Switzerland

P. Erne

Division of Cardiology

Kantonsspital Luzern

Zurich, Switzerland

D. Hayoz

Division of Hypertension

and Vascular Medicine

CHUV

Lausanne, Switzerland
R. Sztajzel

Dept. of Neurology

University of Geneva

Geneva, Switzerland

B. Tettenborn

Neurology Clinic

Kantonsspital St. Gallen

St. Gallen, Switzerland

on behalf of the Swiss Heart Foundation and the Cerebrovascular Working Group of Switzerland

Abstract Background and Purpose Identification of the population at risk of stroke remains the best approach to assess the burden of cardiovascular morbidity and mortality. Methods The prevalence of hypertension (HT), hypercholesterolemia $(\mathrm{HCh})$, diabetes mellitus (DM), overweight (OW), obesity (OB), tobacco use (SM), and their combinations was examined in 4458 Swiss persons (1741 men and 2717 women, mean age $57.8 \pm 15$ years), who volunteered for the present survey. Results OW was the most prevalent risk factor $(50 \%)$, followed by HT (47\%), HCh (33\%), SM (13\%) and DM (1.6\%). The proportion of persons without risk factors (RF) was $19.9 \%$, with $1 \mathrm{RF}$ $41.5 \%, 2$ RF $33.8 \%, 3$ RF $4 \%$, and 4 RF $0.9 \%$. OW was more prevalent in men than in women (53\% vs. $41 \%, \mathrm{P}=0.02)$. More men than women aged $41-50$ years and 51-60 years had HT (49\% vs. $36 \%$, $\mathrm{P}=0.01$, and $52 \%$ vs. $42 \%$, $\mathrm{P}=0.02)$. The prevalence of $\mathrm{HCh}$ and DM did not show any sex-related differences. HT, OW and $\mathrm{HCh}$ were not only the most common single risk factors, but were also most likely to aggregate with each other. Conclusions The majority of Swiss people have one or two vascular risk factors. OW and HT are by far most common and are likely to aggregate with each other. A small modification of these two factors would reduce the incidence of stroke and myocardial infarction significantly.

Key words vascular risk factors - stroke . epidemiology $\cdot$ hypertension . hypercholesterolemia . obesity $\cdot$ Switzerland

\section{Introduction}

Prevention remains the best approach to reduce the burden of stroke despite the availability of thrombolytic treatment for selected patients and the promise of other experimental therapies $[1,2]$. Identification of the population at risk for vascular events and planning of specific interventions is therefore of great importance.

Stroke as a public health problem is not so much the result of individuals with one marked abnormality of a single risk factor. It is more the result of individuals with 
minor abnormalities across a number of risk factors [3]. Clusters of multiple risk factors rather than a single factor determine the cardiovascular risk of the population [4].

Previous population-based studies have assessed the prevalence of single vascular risk factors [5-12], while the prevalence of multiple risk factors has received less attention [13-16]. Important research has focused on the metabolic syndrome, a combination of risk factors leading to insulin resistance and excess risk of cerebrovascular and cardiovascular disease, while other combinations have received little attention.

The aim of the present study was to examine the prevalence of common vascular risk factors and their combinations in a large cohort of healthy Swiss persons, using data from the National Stroke Prevention Campaign of the Swiss Heart Foundation and the Swiss Cerebrovascular Working Group.

\section{Patients and methods}

\section{Data sources and subjects}

The stroke prevention campaign "Meeting Point Heart and Brain" took place in eight shopping malls in Switzerland from February 2001 to September 2001. It was part of the National Stroke Prevention Campaign 2000/2001 entitled "Stroke - Knowing The Risks, Seizing The Chances" organized by the Swiss Heart Foundation in collaboration with the Swiss Cerebrovascular Working Group $[17,18]$.

Supermarkets and shopping malls in Switzerland serve all social classes of the community. Therefore, participants in the present study are very likely to represent all social and ethnic groups within Swiss society.

Overall 4458 persons (1741 men and 2717 women, mean age $57.8 \pm 15$ years, range 4 to 95$)$ participated in the study. They underwent measurements of blood pressure (BP), total cholesterol (TC), blood glucose, body mass index (BMI) and were asked about their smoking habits. Measurements were carried out by physicians and nurses from the neurology and cardiology departments of the nearest community or university hospital. Participants were informed about the results and, if necessary, they were advised to modify their life-style and/or to contact their general practitioner in order to perform additional investigations or to start treatment.

\section{Measurement of blood pressure/Definition of hypertension (HT)}

Persons were seated quietly in a chair, with feet on the floor, and arms supported at heart level [19]. Blood pressure measurements were performed using a brachial cuff and a standardized sphygmomanometer according to the method of Riva-Rocchi. Systolic blood pressure (SBP) was considered the cuff pressure at which the first vascular sound was heard, and diastolic blood pressure (DBP) was the point when sounds disappeared during lowering of the cuff pressure. Two measurements were made in each individual and the mean values of SBP and DBP were documented.

Hypertension was defined as SBP $140 \mathrm{~mm} \mathrm{Hg}$ or greater and/or DBP $90 \mathrm{~mm} \mathrm{Hg}$ or greater. Persons taking antihypertensive medication were also considered hypertensive even when their blood pressure readings were normal [20].

\section{Measurement of total cholesterol/Definition of hypercholesterolemia $(\mathrm{HCh})$}

The total cholesterol (TC) was measured in capillary blood. Hypercholesterolemia (TC values $\geq 6.2 \mathrm{mmol} / \mathrm{l}$ ) was defined according to the recommendations of the National Cholesterol Educational Program (NCEP) for non-fasting testing conditions [21]. Persons with TC values from 5.2 to $6.2 \mathrm{mmol} / \mathrm{l}$ were not considered hypercholesterolemic in the present study. They were advised to contact their family physician in order to perform a fasting lipoprotein profile and to start an appropriate management, if indicated.

\section{Measurements of blood glucose/Definition of diabetes mellitus (DM)}

Levels of fasting and non-fasting glucose in blood were measured in capillary blood. Criteria for the diagnosis of DM were an established disease of diabetes or casual plasma glucose greater than $11 \mathrm{mmol} / \mathrm{l}$ [22].

\section{Measurement of Body Mass Index (BMI)/Definition of overweight (OW) and obesity (OB)}

Body weight was measured in light clothes. The body mass index was calculated by dividing a person's weight in kilograms by height in meters squared.According to the definitions of the American Obesity Association, a BMI between 25.0 to 29.9 was considered overweight and a BMI of 30 or more obese [23].

\section{Definition of current cigarette smoking (SM)}

Current smokers were identified by the question "Do you smoke every day, some days, or not at all?" recommended by the National Center for Health Statistics for estimate of smoking prevalence [24].

\section{Definition of metabolic syndrome (MS)}

Subjects with the metabolic syndrome were defined by criteria similar to those of the Third Report of the National Cholesterol Education Program's Adult Treatment Panel (ATP III) [25], i. e. any three of the following: casual plasma glucose $\geq 11 \mathrm{mmol} / \mathrm{l}, \mathrm{BMI} \geq 30 \mathrm{~kg} / \mathrm{m}^{2}$, blood total cholesterol $\geq 6.2 \mathrm{mmol} /$, blood pressure $\geq 140 / 90 \mathrm{mmHg}$ (or treated hypertension).

\section{Statistical analysis}

Descriptive statistics were performed using SPSS 10 for MacIntosh statistical software $\odot, 2001$, SPSS Inc. Age, blood pressure, blood concentrations of total cholesterol and glucose are given as mean values, standard deviations, minimal and maximal values. The prevalence of individual risk factors and the prevalence of combinations of two or more risk factors were assessed for the entire population, for persons younger than 30 years, for persons of every decade between 30 and 80 years and for persons older than 80 years. The two-sided t-test was used to assess differences between age groups. Values of $\mathrm{P}<0.05$ were considered statistically significant.

\section{Results}

\section{Prevalence of individual risk factors}

The age of the study participants is shown in Tables 1 to 5 . Age groups $<30$ years and $>80$ years were relatively 
small ( $\mathrm{n}=238$ and $\mathrm{n}=141)$ but still sufficiently large to perform a statistical analysis. Overall, 6.1 per 10,000 of the main resident population of Switzerland ${ }^{26}$ participated in the present survey (Table 1). The participation rate among persons older than 40 years reached about 10 per 10,000 inhabitants.

The prevalence of individual risk factors of different age groups is summarized in Table 2. Overweight was the most prevalent vascular risk factor, especially in the seventh decade of life. Fifty eight percent of the persons aged 61 to 70 years and $50 \%$ of all participants had a body mass index of 25-29.9. A BMI $\geq 30$, i. e. obesity, was observed in $11 \%$ of all participants, and among individuals between 61 and 70 years of age in $12.7 \%$. Hypertension was the second most prevalent risk factor (47\%). Its prevalence increased continuously up to the age group $>80$ years $(59.3 \%)$. The prevalence of hypercholesterolemia showed a similar continuous increase with age up to $44.8 \%$ in persons older than 80 years. Diabetes mellitus was diagnosed in $1.6 \%$ of the participants. It was most common among individuals aged $41-50$ years $(2.5 \%)$ and those older than 80 years $(3.4 \%)$. Cigarette smoking was reported by $13 \%$ of the participants. It was more prevalent in the young $(<30$ to 50 years) than among persons aged 51 years and older. Significant differences between age groups are indicated in Table 2 .

\section{Coincidence of vascular risk factors}

The prevalence of persons without a vascular risk factor, with one and with more than one risk factors is summarized in Table 3. The proportion of persons without any of the assessed 5 vascular risk factors was 35\% in the group younger than 30 years and decreased with advancing age. Only $9.2 \%$ of the participants aged 80 years and older were free of any of the 5 risk factors. The overall proportion of persons with one risk factor was $41.5 \%$ and did not differ significantly between the age groups. The coincidence of 2 risk factors was present in $20 \%$ of the participants younger than 30 years. Above this age, the coincidence of 2 risk factors was observed in up to $41 \%$ of the participants. Three risk factors in one and the same person were present in $2.8 \%$ to $4.6 \%$ of all persons. The coincidence of 4 risk factors was rare, less than $1.1 \%$ in participants younger than 80 years of age.

\section{Gender-related differences of individual risk factors}

Overweight was more prevalent in men than in women ( $53 \%$ vs. $41 \%, \mathrm{P}=0.02$ ). This difference was observed in all age groups except the last one ( $>80$ years), where overweight was more frequent among women than among men ( $54 \%$ vs. $39 \%)$. Obesity tended also to be more prevalent in men than women ( $11 \%$ vs. $10 \%)$, but this was not statistically significant. Significantly more men than women aged $41-50$ years and $51-60$ years had hypertensive blood pressure values ( $49 \%$ vs. $36 \%$, $\mathrm{P}=0.01$, and $52 \%$ vs. $42 \%, \mathrm{P}=0.02$ ). The prevalence of hypercholesterolemia and diabetes mellitus did not show any sex-related differences. Men were smoking more often than women ( $18 \%$ vs. $12 \%)$, but the diffe-

Table 1 Participation rate per 10,000 people with respect to age in the main resident population of Switzerland (data extrapolated from the bulletin of the Swiss Federal Statistical Office [26])

\begin{tabular}{lllllll}
\hline Age & $0-19$ years & $20-39$ years & $40-64$ years & $65-79$ years & $>80$ years & Total \\
\hline Study participants & 40 & 555 & 2161 & 1513 & 189 & 4458 \\
Swiss population & 1664865 & 2078962 & 2394244 & 824247 & 299892 & 7262210 \\
$\begin{array}{l}\text { Participation rate } \\
\text { per 10,000 people }\end{array}$ & 0.24 & 2.7 & 9.0 & 18.4 & 6.3 & 6.1 \\
\hline
\end{tabular}

Table 2 Prevalence of individual risk factors of different age groups

\begin{tabular}{|c|c|c|c|c|c|c|c|c|}
\hline \multirow{2}{*}{ Risk factor } & \multicolumn{7}{|l|}{ Age, years } & \multirow[t]{2}{*}{ Overal } \\
\hline & $\begin{array}{l}<30 \\
(n=238)\end{array}$ & $\begin{array}{l}31-40 \\
(n=425)\end{array}$ & $\begin{array}{l}41-50 \\
(n=631)\end{array}$ & $\begin{array}{l}51-60 \\
(n=985)\end{array}$ & $\begin{array}{l}61-70 \\
(n=1256)\end{array}$ & $\begin{array}{l}71-80 \\
(n=782)\end{array}$ & $\begin{array}{l}>80 \\
(n=141)\end{array}$ & \\
\hline Overweight & $28.8 \%$ & $41.5 \%^{\mathrm{a}}$ & $44.4 \%$ & $50.0 \%$ b & $57.5 \%^{a}$ & $52.7 \%^{b}$ & $48.9 \%$ & $50.0 \%$ \\
\hline Obesity & $6.8 \%$ & $8.5 \%$ & $9.0 \%$ & $10.5 \%$ & $12.7 \%$ & $11.7 \%$ & $8.5 \%$ & $10.9 \%$ \\
\hline Hypertension & $32.8 \%$ & $34.8 \%$ & $40.8 \%$ & $44.5 \%$ & $51.0 \%^{d}$ & $55.8 \%$ & $59.3 \%$ & $47.2 \%$ \\
\hline Hypercholesterolemia & $24.0 \%$ & $25.5 \%$ & $25.9 \%$ & $34.3 \%{ }^{e}$ & $38.2 \%$ & $38.3 \%$ & $44.8 \%$ & $33.7 \%$ \\
\hline Diabetes mellitus & $0.6 \%$ & $1.0 \%$ & $2.5 \%$ & $0.9 \%^{\mathrm{b}}$ & $1.1 \%$ & $0.9 \%$ & $3.4 \% c$ & $1.6 \%$ \\
\hline Smoking & $16.9 \%$ & $17.0 \%$ & $17.4 \%$ & $14.9 \%$ & $12.3 \%$ & $8.7 \%^{f}$ & $12.5 \%$ & $13.2 \%$ \\
\hline
\end{tabular}

${ }^{a} P=0.001$, difference to the previous decade; ${ }^{b} P=0.02 ;{ }^{c} P=0.05 ;{ }^{d} P=0.008 ;{ }^{e} P=0.003 ;{ }^{f} P=0.03$ 
Table 3 Prevalence of persons without RF, with $1 \mathrm{RF}$, and with $>1 \mathrm{RF}$

\begin{tabular}{|c|c|c|c|c|c|c|c|c|}
\hline \multirow{2}{*}{$\begin{array}{l}\text { Number of RF } \\
\text { in an individual }\end{array}$} & \multicolumn{7}{|l|}{ Age, years } & \multirow[t]{2}{*}{ Overall } \\
\hline & $\begin{array}{l}<30 \\
(n=238)\end{array}$ & $\begin{array}{l}31-40 \\
(n=425)\end{array}$ & $\begin{array}{l}41-50 \\
(n=631)\end{array}$ & $\begin{array}{l}51-60 \\
(n=985)\end{array}$ & $\begin{array}{l}61-70 \\
(n=1256)\end{array}$ & $\begin{array}{l}71-80 \\
(n=782)\end{array}$ & $\begin{array}{l}>80 \\
(n=141)\end{array}$ & \\
\hline No RF & $35.0 \%$ & $30.6 \%$ & $25.2 \%$ & $18.6 \%^{\mathrm{a}}$ & $14.4 \%^{b}$ & $16.6 \%$ & $9.2 \%$ & $19.9 \%$ \\
\hline $1 \mathrm{RF}$ & $40.6 \%$ & $38.0 \%$ & $39.2 \%$ & $44.5 \%$ & $39.5 \%$ & $43.3 \%$ & $44.6 \%$ & $41.5 \%$ \\
\hline $2 \mathrm{RF}$ & $20.0 \%$ & $28.0 \%$ & $30.2 \%$ & $31.8 \%$ & $41.0 \%^{b}$ & $36.0 \%$ & $36.9 \%$ & $33.8 \%$ \\
\hline $3 \mathrm{RF}$ & $4.3 \%$ & $2.8 \%$ & $4.2 \%$ & $3.9 \%$ & $4.2 \%$ & $3.9 \%$ & $4.6 \%$ & $4.0 \%$ \\
\hline $4 \mathrm{RF}$ & $0.0 \%$ & $0.4 \%$ & $1.1 \%$ & $1.1 \%$ & $0.8 \%$ & $0.2 \%$ & $4.6 \% c$ & $0.9 \%$ \\
\hline
\end{tabular}

$R F$ vascular risk factors

a $P=0.006$, difference to the previous age group; $\mathrm{b} P=0.02 ; c P<0.001$

rence was significant only for the age between 41 and 50 years $(P=0.02)$.

\section{Coincidence of vascular risk factors: gender-related differences}

More women than men were free of vascular risk factors $(24 \%$ vs. $13 \%)$. Differences were significant in age groups $<30$ years ( $39 \%$ vs. $20 \%, \mathrm{P}=0.02), 31-40$ years ( $40 \%$ vs. $15 \%, \mathrm{P}<0.001), 41-50$ years $(30 \%$ vs. $15 \%$, $\mathrm{P}=0.001), 51-60$ years $(20 \%$ vs. $11 \%, \mathrm{P}=0.005)$. One vascular risk factor was equally frequent in men and women up to the age of 80 years. In octogenarians one vascular risk factor was more prevalent in men than in women ( $48 \%$ vs. $12.5 \%, \mathrm{P}=0.005)$. The coincidence of two, three and four risk factors did not differ in men and women ( $30 \%$ vs. $25 \%, 4 \%$ vs. $2.6 \%$ and $1.2 \%$ vs. $0.3 \%$, $\mathrm{P}>0.05)$.

\section{Coincidence of vascular risk factors: most prevalent clusters}

The coincidence of $\mathrm{HT}+\mathrm{OW}$ was the most prevalent combination of vascular risk factors in the cohort $(10.3 \%)$ followed by $\mathrm{HT}+\mathrm{HCh}(6.8 \%)$ and $\mathrm{HCh}+\mathrm{OW}$ (5.6\%). HT + OW + SM, and $\mathrm{HCh}+\mathrm{OW}+\mathrm{SM}$ were the most common triple combinations of risk factors $(1.2 \%$ and $1 \%)$. Clusters of 4 risk factors were rare $(0.8 \%)$. If present, most often $\mathrm{SM}+\mathrm{HCh}+\mathrm{HT}+\mathrm{OW}$ were combined $(0.6 \%)$. The prevalence of the remaining combinations of 2,3 and 4 risk factors was less than $2 \%, 1 \%$ and $0.1 \%$ respectively.

Table 4 indicates the frequency of isolated risk factors and the common combinations in all the age groups.

\section{Prevalence of the metabolic syndrome}

The metabolic syndrome was present in $0.9 \%$ of all participants. It occurred in all age groups and men and women with a similarly low frequency (Table 5).

Table 4 Age distribution of the most prevalent risk factors and clusters

\begin{tabular}{|c|c|c|c|c|c|c|c|c|}
\hline \multirow{2}{*}{$\begin{array}{l}\text { Single risk factors } \\
\text { and clusters }\end{array}$} & \multicolumn{7}{|l|}{ Age, years } & \multirow[t]{2}{*}{ Overall } \\
\hline & $\begin{array}{l}<30 \\
(n=238)\end{array}$ & $\begin{array}{l}31-40 \\
(n=425)\end{array}$ & $\begin{array}{l}41-50 \\
(n=631)\end{array}$ & $\begin{array}{l}51-60 \\
(n=985)\end{array}$ & $\begin{array}{l}61-70 \\
(n=1256)\end{array}$ & $\begin{array}{l}71-80 \\
(n=782)\end{array}$ & $\begin{array}{l}>80 \\
(n=141)\end{array}$ & \\
\hline HT (only) & $10.6 \%$ & $10.3 \%$ & $11.0 \%$ & $13.7 \%$ & $11.4 \%$ & $16.9 \%$ & $15.6 \%$ & $13.2 \%$ \\
\hline OW (only) & $10.6 \%$ & $9.9 \%$ & $11.0 \%$ & $11.9 \%$ & $11.9 \%$ & $8.9 \%$ & $10.4 \%$ & $10.8 \%$ \\
\hline $\mathrm{HCh}$ (only) & $7.9 \%$ & $8.2 \%$ & $8.0 \%$ & $9.7 \%$ & $5.9 \%$ & $8.7 \%$ & $7.8 \%$ & $7.8 \%$ \\
\hline $\mathrm{HT}+\mathrm{OW}$ & $4.6 \%$ & $8.9 \%$ & $10.3 \%$ & $9.0 \%$ & $12.0 \%$ & $11.9 \%$ & $7.8 \%$ & $10.3 \%$ \\
\hline $\mathrm{HT}+\mathrm{HCh}$ & $5.3 \%$ & $5.0 \%$ & $4.8 \%$ & $6.5 \%$ & $8.6 \%$ & $7.7 \%$ & $11.7 \%$ & $6.8 \%$ \\
\hline $\mathrm{HCh}+\mathrm{OW}$ & $5.3 \%$ & $3.9 \%$ & $4.5 \%$ & $5.6 \%$ & $7.0 \%$ & $5.4 \%$ & $6.5 \%$ & $5.6 \%$ \\
\hline$H T+O W+S M$ & $2.0 \%$ & $0.7 \%$ & $1.3 \%$ & $0.6 \%$ & $1.4 \%$ & $1.2 \%$ & $2.6 \%$ & $1.2 \%$ \\
\hline $\mathrm{HCh}+\mathrm{OW}+\mathrm{SM}$ & $0.0 \%$ & $1.0 \%$ & $0.5 \%$ & $1.8 \%$ & $1.1 \%$ & $1.0 \%$ & $1.3 \%$ & $1.0 \%$ \\
\hline $\mathrm{SM}+\mathrm{HCh}+\mathrm{HT}+\mathrm{OW}$ & $0.0 \%$ & $0.4 \%$ & $1.0 \%$ & $0.8 \%$ & $0.6 \%$ & $0.2 \%$ & $1.3 \%$ & $0.6 \%$ \\
\hline
\end{tabular}

$H T$ hypertension; OW overweight; $H C h$ hypercholesterolemia; SM smoking 


\section{Discussion}

Hypertension, tobacco use, high cholesterol and overweight are well recognized risk factors for stroke and myocardial infarction. They belong to the 10 major risk factors for global and regional burden of vascular disease and account for many million deaths worldwide each year [27]. Switzerland is among the countries with low stroke mortality rates. Nevertheless, cardiovascular disorders including stroke are the leading cause of death in Switzerland. There were 25,443 cardiovascular deaths in 1998 and 25,449 such deaths among 62,449 overall deaths in $1999(=40.7 \%)$ [28].

Well-organized and focused prevention has the potential to change the fate of thousands of persons in Switzerland. In order to target prevention, the prevalence of risks has to be known. In this survey, the overall prevalence of overweight (50\%) was most common, followed by hypertension (47\%), hypercholesterolemia $(34 \%)$, smoking $(13 \%)$, obesity $(11 \%)$ and diabetes $(1.6 \%)$. Only $19.9 \%$ of the participants of the present study were free of vascular risk factors. In general, young people and women showed fewer risk factors than men and older people. This may partly explain why women live longer than men in the Swiss population. The prevalence of risk factors increased with advancing age and also combinations of risk factors. Clusters of 2 risk factors were observed in $33.8 \%, 3$ risk factors in $4 \%$ and 4 in $0.9 \%$ of this cohort. Hypertension, overweight and hypercholesterolemia were not only the most common single risk factors, but were also most likely to aggregate with each other (Table 4).

Persons with single risk factors such as hypertension, overweight or hypercholesterolemia and persons with clusters of 2 risk factors should receive special attention in future preventive programs. Their personal risk is lower than the risk of the relatively small fraction of people with more than 2 risk factors. However, an extrapolation of our data to the main resident population suggests that 4,647,814 persons in Switzerland have one or two risk factors and the big bulk of cardio- and cerebrovascular attacks will occur in this large group. A small modification of their risk will have a big impact.

The metabolic syndrome was very rare in this cohort. Compared with the San Antonio Heart and Framingham Offspring studies, the prevalence of the metabolic syn- drome in our cohort was significantly lower $(0.95 \%$ vs. $24 \%$ ) [29]. In part this might be due to a methodological difference. However, our study design did not allow a strict adherence to the ATP III criteria [25]. For instance, many of the glucose measurements were postprandial. Therefore we had to define diabetes by established diagnosis and/or casual plasma glucose greater than $11 \mathrm{mmol} / \mathrm{l}$. It might be that diabetes was underdiagnosed in our cohort. However, even so, the prevalence of the metabolic syndrome in the Swiss population appears to be rather low. In a mass prevention strategy such persons are not the main targets, which - of course - does not mean that they should not receive optimal preventive and medical care once they are identified.

In addition to the prevalence of risk factors at a given time the change of risk factors with time is of interest. In Switzerland, to our knowledge only few data on vascular risk factors were compiled in previous years. The last surveys were conducted in three Swiss communities between 1984 and 1993, within the international research project MONICA (Monitoring of Trends and Determinants in Cardiovascular Disease [30]). The methodology of MONICA and our data collection differed considerably. Therefore, a comparison is not feasible. However, the prevalence of overweight and obesity was significantly higher in this than in the Swiss Nutri-TrendStudy, which was supported by the Swiss Federal Office of Public Health, and was also conducted in 2000 [30]. The most likely explanation of the latter discrepancy are differences in the investigated population. The NutriTrend Study was performed in a random sample of 1004 persons aged 18-74 years who were recruited from all parts of Switzerland.

Recent data from the US Centers for Disease Control and Prevention indicate that nearly two thirds of American adults are overweight, more than $30 \%$ obese and nearly $8 \%$ diabetic, and $24 \%$ have the metabolic syndrome [31]. Thus, the latter vascular risk factors seem to be less prevalent in Swiss than in US American Residents, but also increasing.

Our study has some limitations. It included individuals from all groups within Swiss society, who expressed actively their consent to participate in the examinations. It might be that individuals with previously diagnosed vascular risk factors, personal or familial history of cardiovascular or cerebrovascular diseases were more
Table 5 Prevalence of the metabolic syndrome

\begin{tabular}{|c|c|c|c|c|c|c|c|c|}
\hline & \multicolumn{7}{|l|}{ Age, years } & \multirow[t]{2}{*}{ Overall } \\
\hline & $\begin{array}{l}<30 \\
(n=238)\end{array}$ & $\begin{array}{l}31-40 \\
(n=425)\end{array}$ & $\begin{array}{l}41-50 \\
(n=631)\end{array}$ & $\begin{array}{l}51-60 \\
(n=985)\end{array}$ & $\begin{array}{l}61-70 \\
(n=1256)\end{array}$ & $\begin{array}{l}71-80 \\
(n=782)\end{array}$ & $\begin{array}{l}>80 \\
(n=141)\end{array}$ & \\
\hline Overall & $0 \%$ & $0.71 \%$ & $1.75 \%$ & $1.12 \%$ & $0.63 \%$ & $0.40 \%$ & $1.9 \%$ & $0.95 \%$ \\
\hline Men & $0 \%$ & $1.81 \%$ & $2.41 \%$ & $1.05 \%$ & $1.22 \%$ & $1.16 \%$ & $3.8 \%$ & $1.59 \%$ \\
\hline Women & $0 \%$ & $0.00 \%$ & $0.54 \%$ & $0.96 \%$ & $0.32 \%$ & $0.00 \%$ & $0.0 \%$ & $0.26 \%$ \\
\hline
\end{tabular}


likely to participate. Therefore, inclusion bias cannot be ignored. Self-selection might also explain the predominance of female participants in our study $(61 \%)$. Second, in some individuals the measurements were performed postprandially, which prevented the prevalence of DM to be assessed correctly. Third, data concerning patients' history and treatments were not based on medical records. Therefore, they might have been incomplete in some cases.

In conclusion, the majority of Swiss people have one or two vascular risk factors. Overweight and hypertension are by far most common and are likely to aggregate with each other. A small modification of these two factors would reduce the incidence of stroke and myocardial infarction significantly.

Acknowledgements We thank Pietro Ballinari, $\mathrm{PhD}$, for his statistical advice, and all the volunteers who helped to conduct the Swiss Stroke Campaign. This study was supported by a grant of the Swiss Heart Foundation.

\section{References}

1. Gorelick PB (1995) Stroke prevention. Arch Neurol 52:347-355

2. Sacco RL, Benjamin EJ, Broderick JP, Dyken M, Easton JD, Feinberg WM, Goldstein LB, Gorelick PB, Howard G, Kittner SJ, Manolio TA, Whisnant JP, Wolf PA (1997) American Heart Association Prevention Conference. IV. Prevention and Rehabilitation of Stroke. Risk factors. Stroke 28:1507-1517

3. Australian Institute of Health and Welfare (AIHW) (2001) Heart, stroke and vascular diseases - Australian facts 2001. AIHW Cat. No. CVD 13. Canberra: AIHW, National Heart Foundation of Australia, National Stroke Foundation of Australia (Cardiovascular Disease Series No. 14)

4. Yusuf HR, Giles WH, Croft JB, Anda RF, Casper ML (1998) Impact of multiple risk factor profiles on determining cardiovascular disease risk. Prev Med 27:1-9

5. McGovern PG, Burke GL, Sprafka JM, Xue S, Folsom AR, Blackburn H (1992) Trends in mortality, morbidity, and risk factor levels for stroke from 1960 through 1990. The Minnesota Heart Survey. JAMA 268:753-759

6. Siegel D, Faigeles B (1996) Smoking and socioeconomic status in a population-based inner city sample of African-Americans, Latinos and whites. J Cardiovasc Risk 3:295-300

7. Njolstad I, Arnesen E, Lund-Larsen PG (1996) Body height, cardiovascular risk factors, and risk of stroke in middleaged men and women. A 14-year follow-up of the Finnmark Study. Circulation 94:2877-2882

8. Bots ML, van der Wilk EC, Koudstaal PJ, Hofman A, Grobbee DE (1997) Transient neurological attacks in the general population. Prevalence, risk factors, and clinical relevance. Stroke 28:768-773

9. Sacco RL, Boden-Albala B, Abel G, Lin IF, Elkind M, Hauser WA, Paik MC, Shea S (2001) Race-ethnic disparities in the impact of stroke risk factors: the northern Manhattan stroke study. Stroke 32:1725-1731
10. Bots ML, Elwood PC, Nikitin Y, Salonen JT, Freire de Concalves A, Inzitari D, Sivenius J, Benetou V, Tuomilehto J, Koudstaal PJ, Grobbee DE (2002) Total and HDL cholesterol and risk of stroke. EUROSTROKE: a collaborative study among research centres in Europe. J Epidemiol Community Health 56(Suppl 1):i19-i24

11. Chambless LE, Folsom AR, Davis V, Sharrett R, Heiss G, Sorlie P, Szklo M, Howard G, Evans GW (2002) Risk factors for progression of common carotid atherosclerosis: the Atherosclerosis Risk in Communities Study, 1987-1998. Am J Epidemiol 155:38-47

12. Suk SH, Sacco RL, Boden-Albala B, Cheun JF, Pittman JG, Elkind MS, Paik MC; Northern Manhattan Stroke Study (2003) Abdominal obesity and risk of ischemic stroke: the Northern Manhattan Stroke Study. Stroke 34:1586-1592

13. Kannel WB (2000) Risk stratification in hypertension: new insights from the Framingham Study. Am J Hypertens 13:3S-10S

14. Prevalence of cardiovascular disease risk-factor clustering among persons aged $>$ or $=45$ years - Louisiana, 1991-1995. MMWR Morb Mortal Wkly Rep. 1997; 46:585-588

15. Yusuf HR, Giles WH, Croft JB, Anda RF, Casper ML (1998) Impact of multiple risk factor profiles on determining cardiovascular disease risk. Prev Med 27:1-9

16. Pyorala $M$, Miettinen $H$, Halonen $P$, Laakso M, Pyorala K (2000) Insulin resistance syndrome predicts the risk of coronary heart disease and stroke in healthy middle-aged men: the 22-year follow-up results of the Helsinki Policemen Study. Arterioscler Thromb Vasc Biol 20:538-544

17. http://www.swissheart.ch/content/ hirnschlag/index_hirnschlag-de.html. Web-site last accessed on August 5:2003
18. Bogousslavsky J, Rutishauser W, Mattle H (2000) Hirnschlag-Kampagne der Schweizerischen Herzstiftung (SHS) und Zerebrovaskulären Arbeitsgruppe der Schweiz (ZAS). Schweizerische Ärztezeitung 81:677-679

19. Joint National Committee on Prevention, Detection, Evaluation, and Treatment of High Blood Pressure (2003) The seventh report of the Joint National Committee on Prevention, Detection, Evaluation, and Treatment of High Blood Pressure (JNC VII). NIH Publication No. 03-5233

20. Joint National Committee on Prevention, Detection, Evaluation, and Treatment of High Blood Pressure (1997) The sixth report of the Joint National Committee on Prevention, Detection, Evaluation, and Treatment of High Blood Pressure (JNC VI). Arch Intern Med 157:2413-2446

21. National Cholesterol Education Program (NCEP) (2001) Expert Panel on Detection, Evaluation, and Treatment of High Blood Cholesterol in Adults (Adult Treatment Panel III). NIH Publication No. 01-3670

22. American Diabetes Association (2003) Standards of Medical Care for Patients With Diabetes Mellitus. Diabetes Care 26(Suppl. 1):S33-S50

23. http://www.obesity.org/subs/fastfacts/ obesity_what2. shtml. Web-site last accessed on August 7:2003

24. http://www.cdc.gov/nchs/datawh/ nchsdefs/currentsmoker.htm. Web-site last accessed on August 7:2003

25. National Cholesterol Education Program (NCEP) (2001) Expert Panel on Detection, Evaluation, and Treatment of High Blood Cholesterol in Adults (Adult Treatment Panel III). NIH Publication No. 01-3670

26. http://www.statistik.admin.ch/stat_ch/ ber01/dufr01. htm, Web-site last accessed on December 31:2003 
27. Ezzati M, Lopez AD, Rodgers A, Vander Hoorn S, Murray CJ; Comparative Risk Assessment Collaborating Group (2002) Selected major risk factors and global and regional burden of disease. Lancet 360:1347-1360

28. http://www.statistik.admin.ch/stat_ch/ ber14/eufr14. htm, Web-site last accessed on September 15:2003
29. Meigs JB, Wilson PW, Nathan DM, D'Agostino RB Sr, Williams K, Haffner SM (2003) Prevalence and characteristics of the metabolic syndrome in the San Antonio Heart and Framingham Offspring Studies. Diabetes 52: 2160-2167
30. Eichholzer M, Camenzind E (2003) Übergewicht, Adipositas und Untergewicht in der Schweiz: Resultate der Nutri-Trend-Studie 2000. Schweiz Rundsch Med Prax 90:847-858

31. Bonow RO, Eckel RH (2003) Diet, Obesity, and Cardiovascular Risk. N Engl J Med 348:2057-2058 